\title{
BMJ Global Health Positioning Africa's public health doctoral students to lead societal transformation and development
}

Rawlance Ndejjo, ${ }^{1,2}$ Charles Ssemugabo, ${ }^{1}$ Jimmy Osuret, ${ }^{1}$ Esther Bayiga Zziwa, ${ }^{1}$ Sharon Fonn (D) ," Tobias Alfvén, ${ }^{4,5,6}$ David Mukanga, ${ }^{7}$ Meleckidzedeck Khayesi, ${ }^{8}$ Rhoda K. Wanyenze $e^{1,2}$

\begin{abstract}
To cite: Ndejjo R, Ssemugabo C, Osuret J, et al. Positioning Africa's public health doctoral students to lead societal transformation and development. BMJ Global Health 2022;7:e007996. doi:10.1136/ bmjgh-2021-007996
\end{abstract}

Handling editor Seye Abimbola

Received 13 November 2021 Accepted 23 January 2022

\section{Check for updates}

\section{Author(s) (or their} employer(s)) 2022. Re-use permitted under CC BY-NC. No commercial re-use. See rights and permissions. Published by BMJ.

For numbered affiliations see end of article.

Correspondence to

Rawlance Ndejjo;

rndejjo@musph.ac.ug

\section{ABSTRACT}

The public health context is becoming increasingly more complex requiring highly trained professionals equipped with knowledge, competencies and tools to address or transform current and future challenges. Doctoral degree training offers an opportunity to build the capacity to detect and respond to such dynamic health challenges. In this paper, we discuss how Africa's public health doctoral students can be better positioned for the different career pathways to provide leadership on complex health and development challenges. Public health PhD graduates can take up careers in academia, civil service, private sector and civil society, among others. To thrive in these pathways, PhD training should equip them with knowledge, skills and competencies in leadership, creativity and social competence among others. To produce career-ready PhD graduates, there is need to rethink training curricula to build critical skills for diverse career pathways, introduce students to entrepreneurship, and enhance linkages between universities and industry. Experiential learning, exposure to networks and partnerships, postdoctoral programmes and mentorship and exchange programmes can further equip $\mathrm{PhD}$ students with key knowledge, skills and competencies. For students to position themselves for the different careers, they ought to plan their careers early, albeit with flexibility. Students should build their soft skills and embrace technology among other transferable competencies. By identifying potential career pathways and being positioned for these early, Africa can produce transformative $\mathrm{PhD}$ students on a path for success not just for themselves but for society at large, including in new environments such as that created by COVID-19.

\section{INTRODUCTION}

The public health context is becoming increasingly more complex with challenges of climate change and environmental degradation, emerging and re-emerging infections including pandemics such as COVID-19, and inequities in health access and ouctomes. ${ }^{12}$ Creative and innovative multidisciplinary and multisectoral interventions are needed to address the complex challenges of today and tomorrow. Public health professionals should

\section{Summary box}

Public health doctoral degrees in Africa should equip professionals with knowledge, competencies and tools to effectively deal with the increasingly complex challenges the continent faces.

- Graduates with leadership, creativity and social competence skills would be better positioned for a range of careers including in academia, civil service, private sector and civil society.

- Institutions must rethink the training curricula to build critical skills for diverse career pathways, introduce students to entrepreneurship and enhance linkages between universities and industry as well as introduce postdoctoral training positions.

- Students ought to plan their careers early, although with flexibility, build their soft skills and embrace technology among other transferable competencies.

- By identifying potential career pathways and being positioned for these early, Africa can produce graduates with great potential to transform their society.

thus be equipped with knowledge, skills and tools to detect and respond to these rapidly changing challenges and contexts. They should be trained to work across disciplines and sectors, and geographical and cultural boundaries for appropriate solutions. A doctoral degree is the highest level of training and expertise and is key in building capacity to bridge existing public health competency gaps. Doctoral graduates are expected to use their skills, competencies and voice to provide leadership across the range of public health challenges.

Compared with the rest of the world, Africa has fewer PhDs per capita and contributes least to generating new scientific knowledge. The African continent has only 198 researchers per million people compared with the global average of 1150 and the over 4500 per million in the UK and USA. ${ }^{3}$ Even with $16 \%$ of the world's population, Africa's 
continental research output measured by the amount of peer-reviewed research is less than $1 \% .{ }^{4}$ To achieve just the world average for the number of researchers per capita, the continent needs another million PhDs to develop homegrown solutions. ${ }^{3}$ The 2014 Kigali Communique and the 2015 Dakar Declaration on the revitalisation of African higher education recognise the value of building $\mathrm{PhD}$ capacity in sub-Saharan Africa. ${ }^{5}$ As of July 2021, $32 \%$ of the WHO Africa region's 47 countries did not have postgraduate public health training programmes. ${ }^{6}$ Amidst the low and inconsistent PhD capacity in Africa, there has been limited analysis of the quality and socioeconomic relevance of its outputs. ${ }^{7-10}$ Expansion is, therefore, needed not just in the quantity of PhDs but also in their quality. ${ }^{11}$ To obtain the most value from its $\mathrm{PhDs}$, there is need for appropriate and tailored training and deployment of graduates to contribute to solving the continent's problems. ${ }^{12}$

With the need to increase $\mathrm{PhD}$ graduates across all fields in Africa including in Science, Technology, Engineering and Mathematics, ${ }^{4}$ opportunities should be availed for graduates to make a significant contribution to addressing public health and development problems. Although academia has usually been the go-to field for $\mathrm{PhD}$ graduates, opportunities continue to dwindle in this sector across the world ${ }^{1314}$ and over half of graduates leave the sector due to few opportunities or other reasons. ${ }^{145}$ The limited opportunities for $\mathrm{PhD}$ graduates on the continent has also contributed to their unbalanced emigration especially to the North in search of better opportunities. Career planning in the context of there being inadequate positions in the African academy currently and building the capacity and competencies of $\mathrm{PhD}$ students to work across sectors offers a potential solution to bridge existing gaps ${ }^{1516}$ Several public health training institutions and funding agencies are making efforts to expand $\mathrm{PhD}$ training in Africa. The Consortium for Advanced Research Training in Africa has developed and implemented a collaborative structured $\mathrm{PhD}$ training programme in population and public health to bridge existing competency gaps with significant success. ${ }^{17-19}$ However, substantial gaps remain and the programme focuses on those in academia. ${ }^{17-19}$ This article discusses how Africa's public health doctoral students can be better positioned for the African and global marketplace across different career pathways and lead societal transformation and development on the continent.

\section{CAREER PATHWAYS FOR PHD STUDENTS}

The number of $\mathrm{PhD}$ graduates in Africa is increasing across different fields including Public Health and the need for knowledge generation and competencies including communication and leadership to add value and relevance to society and the development of Africa is paramount more than ever. ${ }^{20}$ For a long time, $\mathrm{PhD}$ graduates have aimed for and built careers in academia and research to the extent that those who fail to get in consider themselves failures, with other sectors considered of lesser value. ${ }^{21}$ This has been compounded by universities focusing on equipping students for academia. As opportunities are decreasing in academia in some parts of the world, ${ }^{13}$ many others have opened up in civil society, civil service and the private sector that $\mathrm{PhD}$ students can pursue and further contribute to dealing with the multiple health and development challenges. In the Netherlands, close to $70 \%$ of $\mathrm{PhD}$ holders work outside academia, even though only $13 \%$ of $\mathrm{PhD}$ students felt well prepared for non-academic jobs. ${ }^{22}$ In the USA, a third of the public health doctoral graduates were employed in non-academic sectors $(31 \%)$ with a similar proportion in academia $(35 \%) .{ }^{21}$ In Africa, however, based on the current demographic profile with a huge proportion of youth now entering higher education, opportunities to remain in academia including in private universities, tertiary institutions and colleges are increasing and thus investments are needed within the academic sector. Beyond producing highly trained $\mathrm{PhD}$ graduates, these investments should extend to research infrastructure, postdoctoral opportunities and mentorship, and sustainable funding for young researchers to ensure that remaining in the African academy is a viable and attractive choice. Academia increasingly requires more comprehensive competencies, beyond teaching and research, to drive transformation of the academy and its contribution, which is urgently required for sustainable development. We discuss four potential career pathways for public health PhD students: academia and research, civil service, civil society and the private sector, and how students can be better positioned for these. Our belief is that students should be led and guided by their passion and the difference they would like to make in the world using the knowledge and skills they have obtained from their $\mathrm{PhD}$ training to thrive in any sector. Although knowledge generation, a key competence of $\mathrm{PhDs}$, is usually viewed as a preserve of academia, we argue that it occurs in a range of institutions and sectors including standalone research institutes and councils, departments within other government institutions, and private organisations. Applying PhD level critical thinking and knowledge generation skills in all these sectors can amplify the contribution of $\mathrm{PhD}$ holders to societal transformation and development. Also importantly, prospective $\mathrm{PhD}$ students should introspect and ensure that knowledge generation is what they are interested in irrespective of which sector they want to apply this skill to.

\section{Academia and research}

Academia is the environment or community concerned with the pursuit of knowledge through research, education and scholarship. Academics are involved in research, teaching, consultancy, professional practice and administration. ${ }^{23}$ They create new knowledge through academic research and teaching in a field of interest with a relatively high degree of autonomy in their work and the possibility of shaping their own identity. ${ }^{23}$ Academics also 
have a worldwide epistemic community and can network physically or virtually with peers from around the world. Through these networking events, academics disseminate and test their findings. An academic career is associated with self-regulation, expert knowledge, high barriers to entry and a widely espoused emphasis on service in contrast to profitability. ${ }^{23}$ The most coveted positions in academia are permanent or confirmed posts, but these are few and extremely competitive. The bulk of academic positions are usually on short contracts which come with less favourable working conditions, job instability and lack of professional recognition affecting satisfaction. ${ }^{24}$ Many times, early career researchers may start with shortterm contracts as they strive to obtain the coveted permanent positions. Beyond academic institutions, $\mathrm{PhD}$ graduates can also join research firms or institutes if they are most interested in research careers.

\section{Civil service}

A career in civil service involves working for a government agency. ${ }^{25}$ Civil servants are officials serving in the permanent administrative arm of government including government ministries, departments and agencies. The civil service personnel usually advise on, develop, and implement government policies and programmes and manage day-to-day activities. Some literature widens the definition of civil servants to teachers, police, military, health workers and public enterprise. ${ }^{26}$ A civil service career may also be international, working for organisations out of one's country including working with United Nations Agencies. While a $\mathrm{PhD}$ may not be required to work at the highest level in in-country civil service in most settings, doctoral graduates can position themselves to work in this sector or internationally. In fact, $\mathrm{PhD}$ holders bring certain advantages to public offices including in conducting evidence synthesis and research, analysing collected data including national surveys, and supporting knowledge generation, translation and evidence-based decision making. Those who have worked in the civil service before taking on $\mathrm{PhD}$ training often take advantage of their experience to continue their work or re-enter the sector if they had left.

\section{Civil society}

Civil society is an arena of uncoerced collective action around shared interests, purposes and values. ${ }^{27}$ The increasingly accepted understanding of the term civil society organisations (CSOs) is that of non-state, notfor-profit, voluntary organisations formed by people in that social sphere. Civil society might include but is not limited to activist groups, charities, civic groups, community/local associations, consumer organisations, foundations, policy institutions, private voluntary organisations and professional associations. ${ }^{28}$ Civil society can deliver services which governments, the private sector or families are unwilling or unable to deliver because of lack of political interest, inflexible public administrations, resource constraints or lack of trust in certain populations. Civil society often employs committed people who are flexible, and responsive to service delivery that the public and private sector organisations alike fail to assemble. CSOs often play a key role in advocacy to drive social change through direct campaigns on topics such as disease awareness or public health issues such as smoking and domestic violence. ${ }^{28}$ To keep states accountable, civil society staff need to lobby governments and advocate for good service delivery to citizens. CSOs also implement and evaluate projects, generate new knowledge, author position papers and mobilise resources for services delivery through grants.

\section{Private sector}

The private sector includes multinational corporations, businesses, industry, management consulting firms, private institutions such as charitable bodies as well as private individuals such as consultants. ${ }^{29}$ The private sector drives the economies of most countries ${ }^{30}$ and creates several opportunities which $\mathrm{PhD}$ graduates can tap into particularly those that are research and development related in small or large enterprises and corporations. The private sector has also been key in manufacturing biomedical products such as diagnostics, therapeutics and vaccines, creating space for knowledge generation and translation. $\mathrm{PhD}$ students can also start their own businesses or offer consultancies to government or other organisations deploying the rich knowledge and skills mix they obtained from the $\mathrm{PhD}$ which often generates new knowledge. In healthcare, there is a current drive towards public-private partnerships in many spheres rather than solely a responsibility of government.

\section{CROSS-CUTTING SKILLS FOR PUBLIC HEALTH PHD GRADUATES}

Public health is a multidisciplinary and interdisciplinary field that requires transferable skills which if well harnessed can position a $\mathrm{PhD}$ graduate for career success. This cross-disciplinary capacity can be applied across a range of sectors including academia, civil service, civil society and the private sectors. Moreover, during a graduate's working life, they are likely to cross over to different sectors or engage in more than one at a given time. Public Health PhD graduates could capitalise on their cross-disciplinary capacity by ensuring that they also have cross-cutting skills. These include project management skills such as in planning activities, scheduling and chairing meetings and conference calls and taking minutes, in addition to grants and scientific writing, evidence synthesis and data analysis. Also useful are communication skills such as using graphics and other tools to create high-quality presentations or illustrations that convey complex information in simple ways for both scientific and lay audiences, teaching and facilitation, advocacy, interpersonal, leadership and teamwork skills. These are critical for any post-PhD career. Extending this by networking within and outside their profession and personal branding such as through websites and available 
social media platforms are also key skills that can assist in the post-PhD career. Students can use LinkedIn to network including posting publications and writing opinion pieces or blogs on topical issues. However, use of such platforms should be responsive to professional standards and organisational guidelines.

Public health PhD training, while focusing on teaching knowledge generation, can assist graduates in developing these additional skills and students should invest some time to acquire them for personal and professional development. Some $\mathrm{PhD}$ programmes provide an avenue for students to teach for specified hours as an inbuilt requirement for the award of the degree. This is a useful way of building critical facilitation skills which employers usually require. ${ }^{31}$ Even when not required by $\mathrm{PhD}$ programmes, students should accumulate some hours of teaching and expand their skills to other key areas such as conducting workshops either virtually or in person and facilitating recess term courses. Presentations at conferences, seminars and meetings, and writing manuscripts and/or dissertations can also greatly improve several oral and written communication skills. Other potential avenues to build skills include mentoring undergraduate or graduate students, taking up leadership roles in the department or PhD student's groups, organising conferences and doing an internship. $\mathrm{PhD}$ students can also manage research and implementation projects, communicate research findings to lay audiences and translate research to policy and action. PhD students can further cultivate skills during training by advocating for student issues or other broader public health matters and mobilising resources for student associations or conferences. Other opportunities include joining think tanks and participating in policy dialogues or stakeholder engagement fora. PhD students can also consider volunteering with a CSO during training to hone these skills and gain exposure to their networks.

PhD students, under supervision, can also undertake assignments from government, civil service or the private sector such as policy-related work, programme evaluations and reviews. Figure 1 summarises potential careers that graduates can engage in and how they can be positioned for opportunities in academia, civil service, private sector and civil society. The framework highlights critical and cross-cutting skills for public health $\mathrm{PhD}$ graduates necessary for the job market and the roles of institutions and students to cultivate them which are further elaborated in the paper. With a variety of options available, students can confidently build successful and fulfilling careers driven and guided by their passion and circumstances.

\section{EQUIPPING PHDS WITH THE SKILLS THEY NEED TO THRIVE}

PhD training can and must equip recipients with knowledge, skills, and competencies to advance specialty areas through conducting original research. Through doctoral training, students can also be equipped with several

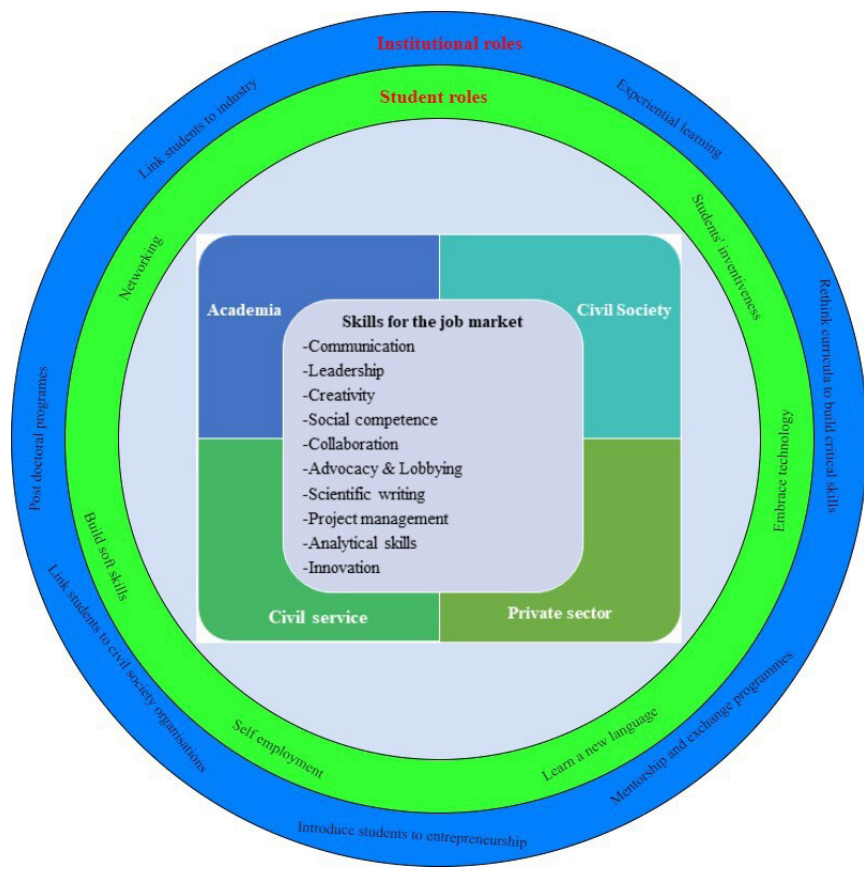

Figure 1 Conceptual framework highlighting cross-cutting skills for public health PhD graduates and roles of institutions and students to cultivate them.

transferable skills that are applicable in a wide range of careers. With the evolution of the career landscape and developmental needs of Africa, these skills become useful in preparing students for a wide variety of career pathways. ${ }^{32}$ We explore ways through which doctoral training can be diverse to produce career-ready $\mathrm{PhD}$ graduates who are critical thinkers with competencies to generate new knowledge.

\section{Rethink curricula to build critical skills for diverse career pathways}

Employers seek PhD graduates with depth and breadth of knowledge and diverse competencies in communication, collaboration, adaptability, research productivity, experiential training, and motivation. ${ }^{33}$ To achieve this, the $\mathrm{PhD}$ academic curricula should prepare students for a broad range of career pathways through building critical practical skills in addition to discipline-specific knowledge. ${ }^{34-36}$ This entails rethinking the curricula to explore important and emerging realities such as information, communication and technology, a switch from problem description to innovations and solution-based orientation, and emphasis on knowledge translation beyond scientific publications. Moreover, beyond being experts with knowledge and skills or professionals with ethical values, universities should train $\mathrm{PhD}$ students to be enlightened change agents with leadership skills. On completion, trainees are expected to generate new knowledge to advance health or other fields and this requires highly skilled and educationally prepared PhDs. ${ }^{37}$ Sinch et al detailed a set of fifteen skills most of which were transferable between research and non-research careers. However, a disconnect was reported between career skills 
needs and those imparted by $\mathrm{PhD}$ training. ${ }^{32}$ Doctoral training programmes should be realigned to increase doctoral students' awareness of multiple career pathways available to them and provide them with skillsets and opportunities required to succeed in diverse careers. Universities should also closely monitor the career outcomes for PhD graduates to better understand local challenges and opportunities and continuously adjust.

\section{Introduce students to entrepreneurship}

Universities can facilitate both social and commercial entrepreneurship for doctoral programmes when they act as incubators allowing students to generate ideas and innovations that solve community health challenges. The role of the university is to file patents and provide resources to help students produce evidence-based products for commercialisation and/or social good. Universities that enhance student entrepreneurial efforts include mentorship and incubator programmes to help startups and offer business plans and funding. ${ }^{38}$ When formal jobs are not immediately available, exposure to entrepreneurship could add to the skillset and opportunities graduates can exploit. Improved linkage between academia and society can be fostered through problemsolving workshops where companies and organisations (private and public) are invited to discuss their challenges and students working with their professors, design interventions to tackle them. Institutions can also have programmes for students to be linked with organisations where they can showcase their skills. These opportunities offer students great exposure to real-world problems and opportunities for jobs or startups after graduation.

\section{Enhance linkages between universities and industry, government and civil society}

Industry, government and civil society need to fully exploit the enormous scientific and technological expertise through university linkages if they are to thrive. This linkage addresses the mismatch between what is taught, and the skills required by other sectors through avenues such as stakeholder engagements, joint conferences, and other networking opportunities. Additionally, it closes the loop between research and its application and enables graduates to gain key skills needed by the sectors positioning them well for multiple careers. The cooperation between governmental and non-governmental organisations (NGOs) and industry can influence demand for PhDs. ${ }^{39}$ Young academics are increasingly confronted with restricted opportunities in academia with many on temporary contracts. ${ }^{40}$ Cognizant of this reality, universities need to ensure exposure to several career fields for informed decision making and career planning for students. When universities and industries cooperate, firms are encouraged to hire $\mathrm{PhD}$ graduates spurring multiple benefits. Some industries have positions for $\mathrm{PhD}$ graduates and these don't have to be scientists with medical backgrounds, but statisticians, psychologists and all the basic sciences are hired providing them a useful way to hone these skills to work in this environment. Universities should maintain an up-to-date inventory of these kinds of opportunities and support their students to apply. Universities should also establish active relationships with these institutions and make the ability of their students known so that they are quickly picked up from a large pool.

\section{Linking $\mathrm{PhD}$ training to the world of work}

The knowledge and competencies of $\mathrm{PhD}$ students can further be enhanced through field experiential learning that uses a model of attachments or placements in the community or institutions. Even though PhDs are meant to be hands-on, far too often, universities have stuck more to theoretical teaching without sufficient exposure to opportunities that can support and enable students to reflect on their learning. Through visiting field sites, engaging in experimental work, and conducting field placements, students are better equipped to understand and tackle community and institutional challenges. The student-centred learning through service provision within communities and institutions also serves as a means of enhancing competence, experience and confidence development as well as community engagement and involvement. The students use the knowledge gained to interact in their placements and in the long run acquire specialised skills including interpersonal and leadership, management, collaboration, communication (risk communication and scientific reporting), systems thinking, critical thinking, advocacy, community engagement and research. The experiential opportunity also gives students and young professionals on-the-job training opportunities and builds their cultural competence. Indeed, beyond scholarship, universities should inculcate cross-cultural understanding among students preparing them to work anywhere in Africa or internationally. ${ }^{36}$

\section{Exposure to networks and partnerships}

Mentors have a role to play to ensure that PhD students and early career researchers have opportunities to get involved in research partnerships and collaborations with national and international organisations, research institutes, and universities. These partnerships are forged through networking and are internal across the university colleges, departments, and institutes attracting multidisciplinary teams. Such partnerships can be North-to-South and South-to-South collaborations which are significant at promoting and supporting research activities and building key collaborative and multidisciplinary skills and multicultural awareness. Mentors can ensure $\mathrm{PhD}$ students are included in these various partnerships. They offer opportunities for joint proposal development, technical support, overseas training, institutional capacity development and the implementation of shared research projects. These further expose PhD students and early career researchers to an enviable set of skills that are important for success in their careers. Key among these 
skills is the ability to work efficiently across sectors and disciplines. Universities often have multiple partnerships and implement research and service projects that could potentially offer practical field opportunities to students and data for their dissertations. Students could also similarly add value to such projects including new ideas and creativity. However, the linkages between these projects, teaching and governmental and non-governmental sectors are sometimes not fully used; supervisors and mentors ought to facilitate this. ${ }^{41}$ Ensuring students and early career researchers are exposed to such networks can be incentivised. Universities and funding institutions should integrate requirements for students to be engaged in funded projects. Other opportunities can also be availed through inter-university and international mobility of students and exchange programmes. Success through cross-institutional collaboration has been proven. ${ }^{42}$

\section{Postdoctoral programmes}

Postdoctoral fellowships offer another avenue for $\mathrm{PhD}$ scholars to thrive in later careers, however, most universities in Africa have no formal postdoctoral mechanisms. Following their doctorates, PhD students can take up postdoctoral fellowships to further establish themselves as independent researchers supporting them to acquire grant funding and develop a publication track record as well as network with other disciplines both nationally and internationally. A study in Canada explored how postdoctoral fellows used their time to prepare for their careers and found that the personal context including prior experience, institutional environment and individuals' present and expected careers and family relationships influenced planning. ${ }^{43}$ Through mentorship from senior researchers, graduates can strategically develop and sharpen their skills ready to launch independent research careers or otherwise.

\section{Mentorship}

Effective PhD mentorship strategies are at three time points that is, prior to a $\mathrm{PhD}$ programme, during a $\mathrm{PhD}$ programme, and in the postdoctoral or early career phase. These strategies enhance the completion rate and establish scholarly independence. Prospective $\mathrm{PhD}$ students should be approached early in their education to interest them in a scientific research-based career. ${ }^{44}$ Provision of mentorship opportunities to young researchers by senior researchers is a common career promoting factor. Young researchers acquire skills when involved in the implementation of research projects. In addition, the provision of seed grant opportunities targeting young researchers enhances interest to pursue a scientific research-based career. ${ }^{44}$ Therefore, the establishment of supportive mentorship programmes, seed grants and training opportunities including exchange programmes are avenues that increase the motivation for participation in research and career advancement for young researchers. ${ }^{45}$

\section{WHAT STUDENTS CAN DO}

Pursuing a career requires a combination of knowledge and experience as well as strategies to position oneself and advance in one's chosen path. Such strategies can be compared to being street-smart, knowing the way around, reading the environment and effectively handling situations that come along. Many universities equip students with book smart knowledge describing the what and why, but street smartness is woven out of experiences and strategies of the how of translating the knowledge into practice or getting yourself into the desired career. Being street smart has no limits and we cannot exhaust the strategies that $\mathrm{PhD}$ students can ably apply to their advantage, but we highlight a few that should serve as a starting point.

\section{Start before and continue during and after PHD}

Career planning starts before doing a PhD and should continue during and after obtaining the qualification. Usually, after PhD, students can either (1) continue with previous careers, (2) change careers or (3) start thinking about a career, especially for those who joined straight from a master's degree. Regardless, PhD students should actively explore potential opportunities while undertaking their programme. They should look for job advertisements to understand the academic and practical requirements being sought for and benchmark their curriculum vitae by applying for these opportunities as well as undertaking internships with potential employers. Students should be proactive in either pursuing their career goals or beginning to think about what career and difference they intend to make in life, whether in national or international civil service, academia, the private or civil society sector and plan to achieve these in a stepwise manner. For instance, $\mathrm{PhD}$ students who are already employed in academia or would like to join this career need to start turning their PhD work into high-quality scientific journal articles and ensure translation of their findings to optimise their competitiveness in this field. Students should create career development plans which are key to enabling them to identify the skills and abilities necessary for career success, seek support and facilitate communication with their mentors. ${ }^{46}$ Career planning should be long term and continuous and if well aligned with individual strengths and passions provide the professional momentum to propel graduates to achieve their desired goals. ${ }^{47}$ Overall, students should actively seek and pursue professional development opportunities as early as possible in their programmes, conduct informational interviews especially through alumni networks and engage in non-academic writing and research opportunities. Such activities give students options and empower them to prepare simultaneously for both academic and other careers. Students should however remain openminded to new possibilities that they may not have planned for. Also, regardless of the route that students take, the importance of networks of peers or groups of 
students and graduates supporting each other through their careers is paramount.

\section{Build the soft skills}

$\mathrm{PhD}$ students ought to deliberately build soft skills while pursuing their PhD degrees. Employers do not only look for technical skills but also soft ones such as leadership (including decision making, taking initiative, teamwork, negotiation, and delivering results and effectiveness), creativity (including problem-solving, critical thinking and innovation) and social competence (including public speaking, networking and persuasion) among others. These skills increase the marketability of $\mathrm{PhD}$ students and will be required regardless of the career path they choose. ${ }^{32} 35$ More critically, these skills are vital to addressing complex public health challenges and transforming society. With the changing demand for $\mathrm{PhD}$ graduates and varied roles that they can take on, these skills can also be turned into illustrious careers such as in science communication using the strong writing and communication skills or data analysis using data management and analytical skills. A survey among science PhD students in the US noted an increasing interest in careers such as science communication/writer, science policy, non-university teaching, working for a non-profit/NGO and consulting. ${ }^{40}$ By being proactive, students can map out upcoming specialisations that will emerge in the next decade or so, which now may include artificial intelligence, digitisation as well as do-it-yourself strategies and deliberately position themselves with key relevant skills. PhD students should thus have a deliberate plan to cultivate relevant soft skills including through teaching university courses, presenting their works at different fora, organising and/or attending conferences, running a lab and applying for grants. ${ }^{32}$ Participation in mentorship, training, competitions and exchange programmes during $\mathrm{PhD}$ training are other avenues for developing these competencies. If several $\mathrm{PhD}$ holders apply for the same opportunity, their skillset and experience may usually make the difference on who is hired. Beyond being a scholar with deep subject-specific expertise, $\mathrm{PhD}$ students can be a professional with skills valued in today's complex workforce. Making the most use of available opportunities also helps $\mathrm{PhD}$ students to prepare for a greater diversity of career options.

\section{Embrace technology}

One of the hallmarks of the 21st century has been the rapid adoption and use of technology in almost all spheres of life. Technology has created many job opportunities that were unheard of a decade or two ago. These include digital marketing specialist, social media manager, blogger, software application developer and cloud services specialist. In addition, big data analyst (data scientist), telemedicine physician, podcast producer, YouTube content creators and drone operators have also emerged. The COVID-19 pandemic has further accelerated the shift towards widespread adoption of technology including in teaching and learning, healthcare and other services delivery, and modified working environments and cultures. ${ }^{48}{ }^{49}$ One certainty is that technology will be further entrenched in society and students should embrace it early and learn as much as possible as techsavviness may be required in any career placements just after school or a decade later. Put simply, students should for example have a LinkedIn profile that they should update regularly and use together with other avenues to network and connect across boundaries, continuously seek to innovate and integrate technology into their fields of work and further develop their capacity in using varied technology tools. Universities should advance their technological infrastructure and systems to better support students and hone their technological competencies as well as those of the academics.

\section{The self-employment route}

PhD students can also explore becoming employers through creating their own companies and ventures that serve the needs of society. In a survey among over $3000 \mathrm{PhD}$ students in the Flemish universities, 14\% indicated interest in self-employment as a major activity and $34 \%$ as a secondary activity. Among respondents, $15 \%$ of respondents rated their chances of being selfemployed in the future as high or very high. ${ }^{50}$ Whereas it is understandable that not every $\mathrm{PhD}$ student can set up a company such as to offer consultancy services, the few that already have their own companies or have an entrepreneurial orientation can explore this path. Success in this path will also still rely on the soft skills that the $\mathrm{PhD}$ graduate acquired along the way including commitment, resilience, networking and communication skills, and emotional intelligence.

\section{Learn a new language}

$\mathrm{PhD}$ students can also further set themselves apart by learning an additional language. English has stood out as the language of scholarship and non-English speaking PhD students may be disadvantaged in the opportunities they have access to. Moreover, with current globalisation efforts, the need to speak, read and write more than one international language would increase the scope of opportunities for PhD students and make them more competitive. Thus, even when one is fluent in English, being able to speak other international languages including French, Spanish, Russian, Arabic, and Chinese will naturally set some $\mathrm{PhD}$ students apart and position them for a multitude of opportunities, especially in multinational and multicultural environments. There is consensus between employers and graduate students that English is a key determinant of employability as well as the ability to communicate in other languages. ${ }^{51}$

\section{CONCLUSION}

For Africa PhDs to significantly contribute to addressing the complex challenges it faces, generate knowledge, and transform the continent, the importance of deliberate, 
well-curated career paths cannot be overstated. We have explored what careers in academia and research, civil service, civil society and the private sector may mean for public health $\mathrm{PhD}$ graduates and offered insights on how to thrive in them. To enhance the contribution and preparedness of $\mathrm{PhD}$ students, there is need to rethink curricula to build critical skills for diverse career pathways, introduce students to entrepreneurship, and enhance linkages between universities and industry, government and civil society. Moreover, the value of exposure to real-life working conditions, networks and partnerships, mentorship and postdoctoral programmes remains paramount. For students to position themselves for the different career pathways, they ought to start early, build their soft skills in leadership, creativity and social competence, and embrace technology. Where possible, capitalising on their self-employment skills or learning a new language can also be of great advantage. The career pathways are interrelated and sometimes graduates can be in more than one career path at a given time or switch from one career to another along the way and thus the need to remain open-minded. By identifying potential career pathways and being positioned for these early, Africa can produce transformative $\mathrm{PhD}$ students on a path for success not just for themselves but for society at large.

\section{Author affiliations \\ ${ }^{1}$ Department of Disease Control and Environmental Health, School of Public Health, College of Health Sciences, Makerere University, Kampala, Uganda \\ ${ }^{2}$ Centre of Excellence for Sustainable Health, a Collaboration Between Makerere University and Karolinska Institutet, Kampala, Uganda \\ ${ }^{3}$ School of Public Health, University of the Witwatersrand, Johannesburg, South Africa \\ ${ }^{4}$ Department of Global Public Health, Karolinska Institutet, Stockholm, Sweden ${ }^{5}$ Centre of Excellence for Sustainable Health, a Collaboration Between Makerere University and Karolinksa Institutet, Stockholm, Sweden \\ ${ }^{6}$ Sachs' Children and Youth Hospital, Stockholm, Sweden \\ ${ }^{7}$ Bill \& Melinda Gates Foundation, Seattle, Washington, USA \\ ${ }^{8}$ Injuries and Violence Prevention Department, World Health Organization, Geneva, Switzerland}

Twitter Rawlance Ndejjo @rawleng

Acknowledgements The authors wish to acknowledge the PhD Forum at Makerere University School of Public Health from where the discussions that led to this article emerged.

Contributors RN, CS, JO, EBZ, DM, MK and RKW conceptualised the manuscript and were involved in its writing. RN, CS, J0 and EBZ conducted the literature review and wrote the first draft of the manuscript. SF, TA, DM, MK and RKW critically reviewed and revised the draft manuscript. All authors reviewed and approved the final version of the manuscript.

Funding The authors have not declared a specific grant for this research from any funding agency in the public, commercial or not-for-profit sectors.

Competing interests None declared.

Patient and public involvement statement Not applicable

Patient consent for publication Not applicable.

Ethics approval This study does not involve human participants.

Provenance and peer review Not commissioned; externally peer reviewed.

Data availability statement Data sharing not applicable as no datasets generated and/or analysed for this study.
Open access This is an open access article distributed in accordance with the Creative Commons Attribution Non Commercial (CC BY-NC 4.0) license, which permits others to distribute, remix, adapt, build upon this work non-commercially, and license their derivative works on different terms, provided the original work is properly cited, appropriate credit is given, any changes made indicated, and the use is non-commercial. See: http://creativecommons.org/licenses/by-nc/4.0/.

ORCID iD

Sharon Fonn http://orcid.org/0000-0001-6115-8707

\section{REFERENCES}

1 Watts N, Amann M, Arnell N, et al. The 2020 report of the Lancet countdown on health and climate change: responding to converging crises. Lancet 2021;397:129-170.

2 Gostin LO. The great coronavirus pandemic of 2020-7 critical lessons. JAMA 2020;324:1816-7.

3 Christoffels A. Africa needs another million PHD scientists to develop homegrown solutions. Quartz Africa, 2018.

4 Lan G, Blom A, Kamalski J, et al. A decade of development in subSaharan African science, technology, engineering and mathematics research. Elservier, editor World Bank, 2014.

5 Molla T, Cuthbert D, DJPFiE C. In pursuit of the African PHD: a critical survey of emergent policy issues in select sub-Saharan African nations, Ethiopia, Ghana and South Africa. Policy Futures Educ 2016;14:635-54.

6 Centre for Capacity R. Annex 2 - Master List of HEls. V1 ed: Harvard Dataverse, 2021. Available: https://doi.org/10.7910/DVN/Q8CNY3, Harvard Dataverse, V1

7 Mentz-Coetzee M, Stroebel A, Swanepoel F. The Significance of Doctoral Education and Training for Development in Sub-Saharan Africa. In: Education and development. Springer, 2020: 199-221.

8 IAU. Changing nature of doctoral studies in sub-Saharan Africa: challenges and policy development opportunities at six universities in sub-Saharan Africa. Paris, 2012.

9 IAU-ACUP. Report of the "IAU-ACUP International Seminar on Innovative Approaches to Doctoral Education and Research Training in sub-Saharan Africa.". Addis Ababa, 2012.

10 Bunting I, Cloete N, FJARotHER vanS. Transformation ANiACTCfHE. In: An empirical overview of eight flagship universities in Africa, 2014.

11 British Council. Deutscher Akademischer Austauschdienst. In: Building PHD capacity in sub-Saharan Africa, 2018.

12 Fonn S. African PhD research capacity in public health: raison d'etre and how to build it. Global Forum for Health Research Geneva, 2006.

13 Larson RC, Ghaffarzadegan N, Xue Y. Too Many PhD Graduates or Too Few Academic Job Openings: The Basic Reproductive Number $R_{0}$ in Academia. Syst Res Behav Sci 2014;31:745-50.

14 Neumann R, Tan KK. From PHD to initial employment: the doctorate in a knowledge economy. Stud High Educ 2011;36:601-14.

15 Barnacle R, Dall'Alba G. Research degrees as professional education? Stud High Educ 2011;36:459-70.

16 McAlpine L, Turner G. Imagined and emerging career patterns: perceptions of doctoral students and research staff. J Furth High Educ 2012;36:535-48.

17 Fonn S, Egesah O, Cole D, et al. Building the capacity to solve complex health challenges in sub-Saharan Africa: CARTA's multidisciplinary PHD training. Can J Public Health 2016;107:e381-6.

18 Balogun FM, Malele-Kolisa Y, Nieuwoudt SJ, et al. Experiences of doctoral students enrolled in a research fellowship program to support doctoral training in Africa (2014 to 2018): the Consortium for advanced research training in Africa odyssey. PLoS One 2021;16:e0252863.

19 Ezeh AC, Izugbara CO, Kabiru CW, et al. Building capacity for public and population health research in Africa: the Consortium for advanced research training in Africa (CARTA) model. Glob Health Action 2010;3:5693.

20 Jowi JO. Doctoral training in African universities:recent trends, developments and issues. J Br Acad 2021;24:159-81.

21 Brown-Podgorski BL, Holmes AM, Golembiewski EH, et al. Employment trends among public health doctoral recipients, 20032015. Am J Public Health 2018;108:1171-7.

22 OECD. Reducing the precarity of academic research careers, 2021.

23 Boden R, Kenway J. Building your academic career: theory, practice and reform. London: SAGE publications Ltd, 2005: $132 \mathrm{p}$.

24 Waaijer CJF, Belder R, Sonneveld H, et al. Temporary contracts: effect on job satisfaction and personal lives of recent PHD graduates. High Educ 2017;74:321-39. 
25 Avis W. Factors important to the establishment, renewal or rehabilitation of the civil service. Birmingham, UK: University of Birmingham, 2015.

26 Rao S. Civil service reform: topic guide. Birmingham, UK: University of Birmingham, 2013

27 Jaysawal N, Society C. Democratic space, and social work. SAGE Open, 2013.

28 Greer SL, Wismar M, Kosinska M. What is civil society and what can it do for health? In: Civil Society and health: contributions and potential chapter 1. Copenhagen (Denmark): European Observatory on health systems and policies, 2017.

29 Hallo De Wolf A, Toebes B. Assessing private sector involvement in health care and universal health coverage in light of the right to health. Health Hum Rights 2016;18:79-92.

30 UNESCO. Empowering the private sector to drive economic growth in low-income countries. Paris: France: United Nations Educational, Scientific and Cultural Organisation, 2016.

31 Chong Z-S, Clohisey S. How to build a well-rounded cv and get hired after your PHD. Febs J 2021;288:3072-3081.

32 Sinche M, Layton RL, Brandt PD, et al. An evidence-based evaluation of transferrable skills and job satisfaction for science PhDs. PLoS One 2017;12:e0185023.

33 McLaughlin JE, Minshew LM, Gonzalez D, et al. Can they imagine the future? A qualitative study exploring the skills employers seek in pharmaceutical sciences doctoral graduates. PLoS One 2019;14:e0222422.

34 Falkenberg-Olson AC. Research translation and the evolving PHD and DNP practice roles: a collaborative call for nurse practitioners. $J$ Am Assoc Nurse Pract 2019;31:447-53.

$35 \mathrm{H}-\mathrm{f}$ L, Miozzo M, Laredo P. Career patterns and competences of $\mathrm{PhDs}$ in science and engineering in the knowledge economy: the case of graduates from a UK research-based university. Research Policy 2010;39:869-81.

36 Hornsby DJ, Arvanitakis J. The citizen Scholar in developing global perspectives. The globalisation of higher education. Springer 2018: 149-64.

37 Mathur A, Chow CS, Feig AL, et al. Exposure to multiple career pathways by biomedical doctoral students at a public research university. PLoS One 2018;13:e0199720.
38 Boh WF, De-Haan U, Strom R. University technology transfer through entrepreneurship: faculty and students in spinoffs. J Technol Transf 2016;41:661-9.

39 Garcia-Quevedo J, Mas-Verdú F, Polo-Otero J. Which firms want PhDs? an analysis of the determinants of the demand. High Educ 2012;63:607-20.

40 Sauermann H, Roach M. Science PHD career preferences: levels, changes, and advisor encouragement. PLoS One 2012;7:e36307.

41 Manderson L, Bondjers G, Izugbara C. Enhancing doctoral supervision practices in Africa. J High Edu Africa/Revue de I'enseignement supérieur en Afrique 2017;15:23-40.

42 Uwizeye D, Karimi F, Otukpa E, et al. Increasing Collaborative research output between early-career health researchers in Africa: lessons from the CARTA fellowship program. Glob Health Action 2020;13:1768795.

43 Chen S, McAlpine L, Amundsen C. Postdoctoral positions as preparation for desired careers: a narrative approach to understanding postdoctoral experience. High Educ Res Dev 2015;34:1083-96.

44 Stanfill AG, Aycock D, Dionne-Odom JN, et al. Strategies and resources for increasing the PHD pipeline and producing independent nurse scientists. J Nurs Scholarsh 2019;51:717-26.

45 Kramer B, Libhaber E. Closing the barrier between disease and health outcomes in Africa through research and capacity development. Glob Health Action 2018;11:1425597.

46 Hobin JA, Clifford PS, Dunn BM, et al. Putting PhDs to Work: Career Planning for Today's Scientist. CBE Life Sci Educ 2014;13:49-53.

47 Shirey MR. Building an extraordinary career in nursing: promise, momentum, and harvest. J Contin Educ Nurs 2009;40:394-400.

48 Ting DSW, Carin L, Dzau V, et al. Digital technology and COVID-19. Nat Med 2020;26:459-61.

49 Whitelaw S, Mamas MA, Topol E, et al. Applications of digital technology in COVID-19 pandemic planning and response. Lancet Digit Health 2020;2:e435-40.

50 Mortier A, Levecque K, Verlinden L. Life after... or next to the PhD: how PhD candidates look at a career of self-employment: ECOOM brief 23, 2020.

51 Zainuddin SZB, Pillai S, Dumanig FP, et al. English language and graduate employability. ET 2019;61:79-93. 